\title{
Exploring Interactive Simulations as a Powerful Tool in STEM-PBL Approach in Physics
}

\author{
Mariana Mirela Stanescu, \\ Faculty of Applied Sciences, Polytechnic University of Bucharest, Romania \\ Doi:10.19044/esj.2020.v16n21p1 \\ URL:http://dx.doi.org/10.19044/esj.2020.v16n21p1
}

\begin{abstract}
Recent educational studies have shown that interactive simulations in teaching science can improve motivation, understanding and active learning. This article aim was to investigate potential of interactive simulation in STEM approach in the case of complex phenomena related to light. PhET is a learning environment that integrates virtual labs for various disciplines, widely used in education. The descriptive research method achieved its goal and confirmed that simulations in physics represent a valuable tool for the acquisition and consolidation of STEM skills.
\end{abstract}

Keywords: STEM, Light, Interactive Simulations, Key Skills, Motivation

\section{Introduction}

Science, technology, engineering and mathematics (STEM) are nowadays fundamental for the progress of humanity and for improving the quality of life.

Beyond simple basic skills, modern education is based on the formation of new skills, such as technology education, information literacy and information and communication technology (ICT) literacy (Mohagheghzadeh et al., 2014).

In the past years, there were a lack of interest in STEM disciplines that are recognized as STEM crises in international reports from Australia, Canada, India, Japan, U.K. and the U.S.A. (Nakakoji and Wilson, 2018). Without a solid foundation in mathematics and science and In elementary and middle school, students may feel unprepared to pursue a career in the field of STEM.

Interdisciplinarity is considered indispensable for future scientists and engineers, economic development scientific literacy for modern citizenship.

There are more and more innovative programs and policies that promote interdisciplinary learning as a key approach to the learning process. 
The modern educators face the low interest of the students for study and the lack or inadequacy of the laboratory equipment. The acquisition of skills and knowledge is not complete unless the students continue with the individual study.

According to the teachers surveyed in a study (Lazar, 2018) disciplines advantaged by ICT use are Sciences (physics, chemistry or biology) as indicated by $59.7 \%$ of the respondents.

Learning outcomes are best predicted by prior learning in any field.

Mathematics is fundamental to science and engineering and it has been argued that we can understand it as a language for describing the laws of physics.

Physics uses symbols and equations from mathematics wich is consistently the most influential interdisciplinary predictor of learning outcomes (Anderton, et al., 2017). Mathematical skills (calculation, synthesis, interpretation, extrapolation) influence achievements in learning physics (Omeodu, 2019).

Nobel laureate Carl Wieman created a set of interactive math and science exercises: PhET, the University of Colorado's interactive simulation project, that was launched in 2002.

$\mathrm{PhET}$ simulations are based on extensive education researching and training students in an intuitive, game-like environment. Here students can learn STEM topic through exploration and discovery.

Phet is an educational platform that allows access to virtual laboratories, for various disciplines widely used in education. There are 154 interactive simulations, translated into 98 languages and 1994 teachersubmitted lessons.

All of these can be accessed free of charge and can be integrated into teaching, learning and assessment activities. The students' creativity and independent learning are being developed and exploited.

Studies (Perkins et al., 2006) have shown that simulations can be used to highlight connections between real-life phenomena and basic science.

It is proven that integrating virtual labs into science learning has an impact on self-confidence.

The research (Wickham et al., 2016) provides statistical evidence that these simulations have significantly improved the students' attitude towards physics and their confidence in the subjects studied.

Learning by using PheT simulations can improve critical thinking skills. The use of new devices (tablets or smartphones, which can produce simulations and virtual animations) has the potential to support scientific inquiry (Ferty et al., 2019). 


\section{Methodology}

The nature of light, its dual character are difficult topics to tackle. Interference and diffraction are phenomena that are sometimes difficult to observe in the laboratory, either due to the poor equipment or the small number of hours allocated in the curriculum.

A research-based approach can be used to understand the concepts of physics related to light. The project can include theoretical and experimental arguments that the students find and sustain.

This research aims at proposing a framework of the STEM concepts and applications that needs to be integrated in the Physics interdisciplinary approaches for the nature of light and phenomena.

\section{Research purpose:}

To investigate the really potential of physics simulations to teach and learn in the STEM approach the complex concept of light.

The importance of this research consists in the approach that highlight the valences and the role of these simulations in the realization of the Physics curriculum.

The research results can be valuable for the educational policies that must take into account the harmonization of the integrated STEM concepts in the content development of the school curricula.

The results can also serve as good practices in the training of science teachers.( Ukoh, 2012)

Physics curriculum, national standards, STEM competences, concepts and PHET applications were chosen as research tools and materials that need to be analyzed.

In this research the descriptive method was chosen to analyze literature basis, theories and projects, content of Physics curricula. It was also used in elaborating the STEM concepts and applications to be integrated in the Phet based lessons of Physics. (Stanescu, 2017; Iancu \& Chilom, 2016).

For the purposes of the study, Physics textbooks and curriculum of 11 grade of secondary education were content analyzed, as well as Phet simulations related to topic Nature of light: Interference and diffraction Phenomena.

\section{Results}

According the national standards for teaching Physics in preuniversity education (Physics) the competences/skills associated to this STEM interference approach are: 


\section{Key competences}

1. Understanding and explanation of some physical phenomena, some technological, processes, operation and the use of products and techniques in everyday life- Science, technology, engineering and mathematics skills (STEM

2. Qualitative and quantitative analysis of the phenomenon of

3. Interference, specifying the conditions for obtaining stationary interference- SM skills

4. Qualitative analysis of energy distribution in interference/diffraction and stationary interference- STEM skills

5. Experimental investigation of light interference using non-localized interference devices- STE

6. Qualitative and quantitative explanation of the operation of some non - localized interference devices (Young device and Davisson and Germer device)-STEM skills

7. Use of simple interference devices in determination of light characteristics-SE skills

8. Solve light interference problems in non-localized interference devices-STM skills

\section{A. Interference and diffraction reveal the wave nature of light.}

Students should analyze arguments, observing and considering observations, making induction and considering the results of induction, define terms and consider definitions and decide an action.

Students will be able to (Phet. a):

- Learn to produce waves with water, sound and light and see how they are connected.

- Design an experiment to measure the wave speed (with the measuring tape and chronometer.

- Create an interference model with two sources and determine how to change the model.

- Find points of constructive and destructive interference using detectors.

- Observe what kind of pattern creates the light moving through one or two slits and how can be changed. 


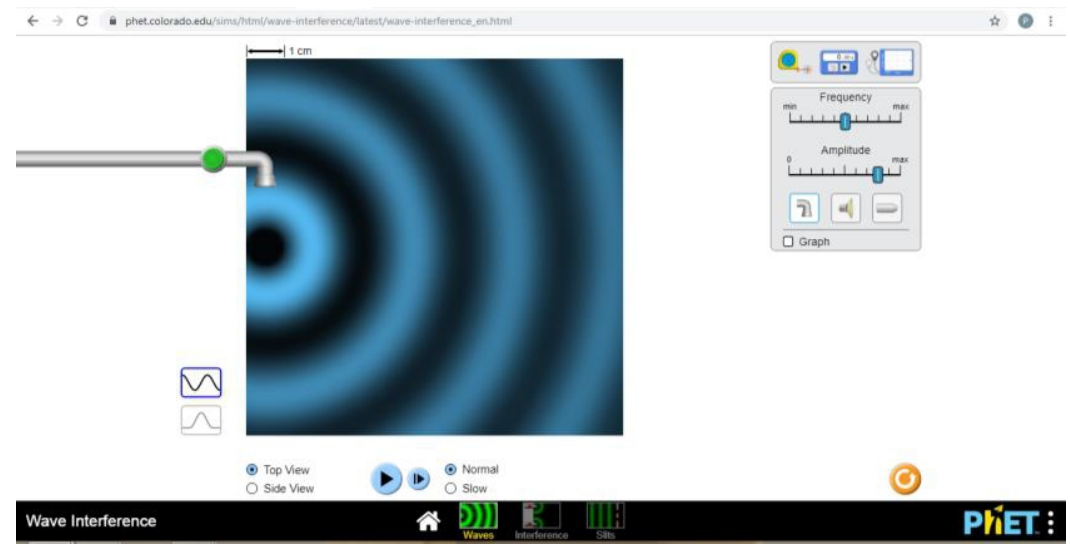

Figure 1. Types of waves (water). ( Phet b)

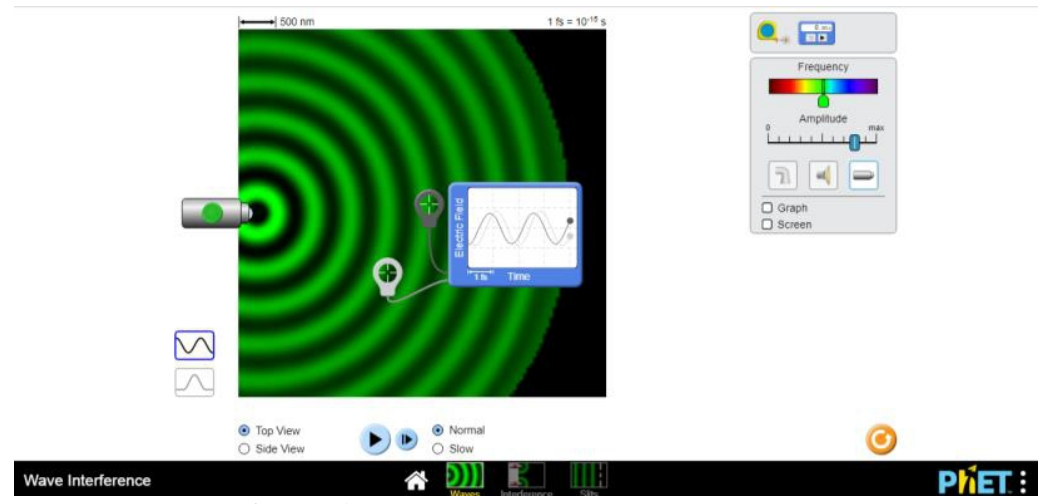

Figure 2. Types of waves (light). ( Phet b)

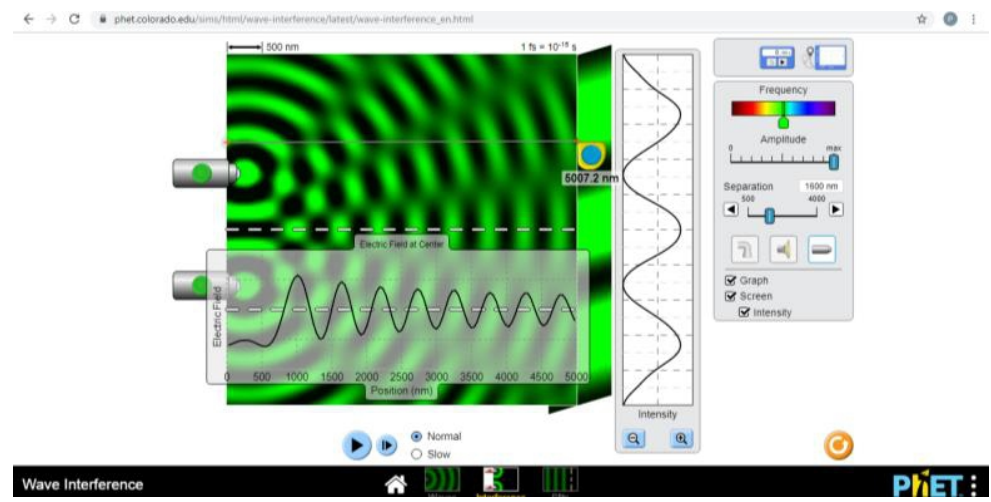

Figure 3. The interference of waves (green light). ( Phet b) 


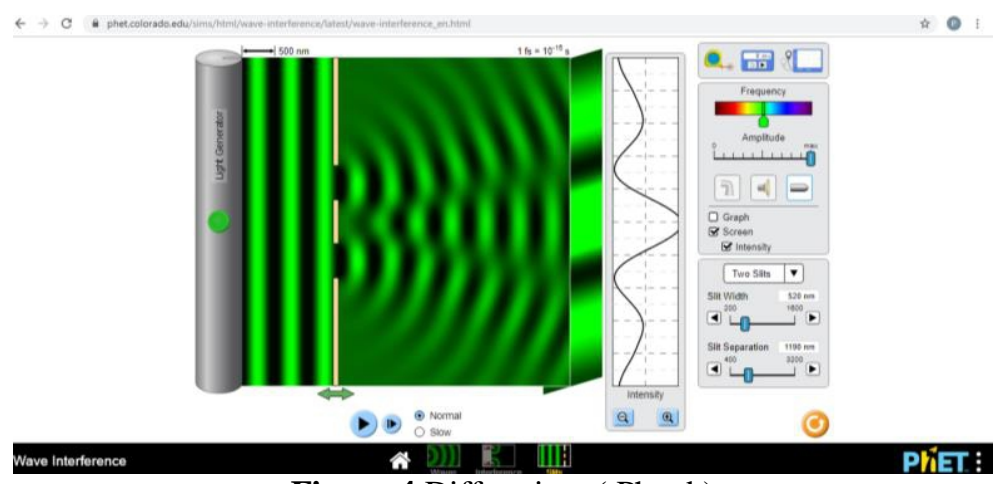

Figure 4.Diffraction. ( Phet b)

Students can observe the difference between interference and diffraction, the pattern depends on the width and separation of the slits and the position of barrier.(fig.3-4)

$$
\mathrm{i}=\frac{\lambda D}{d}
$$

where i means distance between two consecutive fringes, $D=$ the position of barrier, $\mathrm{d}=$ separation of the slits

They will be able to recognize phenomena by every fringe pattern intensity. With the help of the measuring tape and the detectors( fig.3), students can verify and predict the locations of the fringes that appear on the screen using relation (2) of the Young double slits experiment.( Phet b)

$$
\mathrm{x}_{\max }=\frac{k \lambda D}{d}
$$

where $\mathrm{k}$ means the order of maximum intensity at distance $\mathrm{x}_{\max }$ from the central maximum fringe.

\section{B. The photoelectric effect shows light as having a particle-like character}

Electrons can be diffracted like waves, although they have mass. Author has chosen Davisson and Germer simulation as relevant. It simulates the experiment which proved that electrons behave like waves. Accelerated electrons are diffracted on a metallic crystal, thus peaks and troughs of probability appear. (Figures 5, 6) 


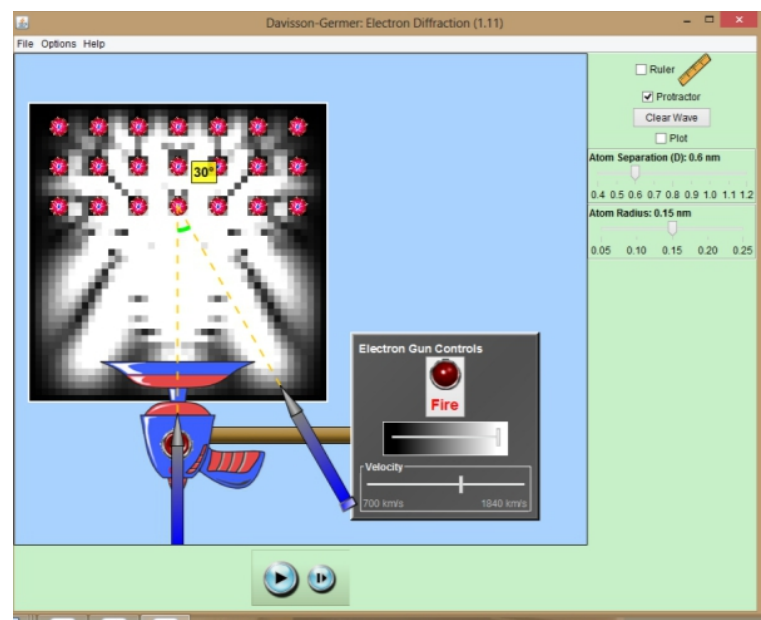

Figure 5. Davisson and Germer experiment. (phet c)

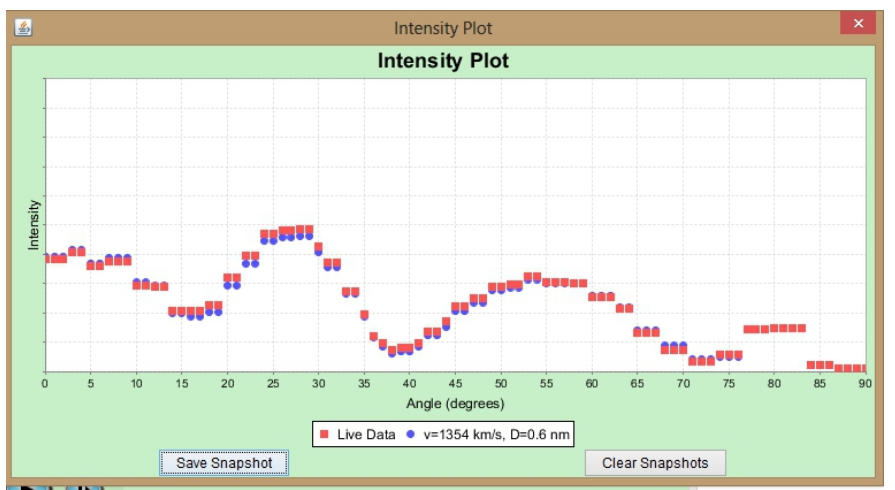

Figure 6. Davisson and Germer experiment.Intensity plot.( Phet c)

With determined angles (Figure 6) students can calculate the wavelength associated with electrons and can verify Louis de Broglie hypothesis.

For example:

The first diffraction maximum $(\mathrm{k}=1)$ appears at $\theta=27^{\circ}$, from simulation $\mathrm{D}=$ $0,6 \mathrm{~nm}$ ( atom separation)

$$
2 \mathrm{~d} \sin (\theta)=\mathrm{k} \lambda \text { we obtain } \lambda=0,544 \mathrm{~nm} .
$$

And according to de Broglie formula

$$
\lambda=\frac{h}{m v}=0,537 \mathrm{~nm} \quad \text { (from simulation the speed value } \mathrm{v}=1354 \mathrm{~km} / \mathrm{s} \text { ) }
$$

Niels Bohr assumed that the wave model and the particle model allow us a complementary perception of reality. Neither provides the complete or perfect image. Students must decide on the theory and present evidence STEM projects to support their decision. 


\section{Conclusion}

The computer simulations can be easily integrated into different types of teaching and learning approaches. Thus, learning is improved. (Develaki, 2019)

The research achieved its goal and confirmed that simulations in physics represent a valuable and multivalent tool for the acquisition and / or consolidation of STEM skills.

The advantages of simulations of phenomena characteristic of light must be emphasized:

-In the real laboratory the measurement / observation time is limited; in the virtual one, students can repeat the experiment at home and restore / improve the experimental data. In this way the working hypotheses can be verified with a better precision.

Students must conduct and report these scientific investigations to the teacher and colleagues. They can compare virtual experimental data, formulate ideas and test hypotheses. Error sources can be better managed than in the real lab.

-Students thus understand abstract scientific ideas and concepts; learn to sustain theoretically the investigation.

This kind of approach creates a synergetic relationship between the learning of the sciences and the quality of the scientific discourse.

Because not all simulations are translated into Romanian, CLIL-type lessons and course can also be designed.

Curriculum worldwide can be reinforced in order of including more STEM topics. The teachers can imagine and use interdisciplinary project based learning (PBL) lessons- i.e. light and nanotechnology concepts with a huge impact on students interest in science - blue butterfly and the phenomenon of light diffraction-Nano-laser applications) (Abdul Salam et al, 2015).

The concepts of modern physics must be introduced innovatively to support technological and educational needs to valorize necessary scientific and cognitive skills, to model them in accordance with the development of society and technology. Increase of awareness of physics teachers about the importance of STEM concepts applications and teaching methods is necessary.

\section{References:}

1. Abdul Salam, S., Ramadan, S., Al-Tantawi.A.-H., Al-Zaini, S. A.,(2015). Integrating Nanotechnology Concepts And Its Applications Into The Secondary Stage Physics Curriculum In Egypt. European Scientific Journal . 11(12) 
2. Anderton, R., Hine, G., Joyce, C. (2017) Secondary school mathematics and science matters: Academic performance for secondary students transitioning into university allied health and science courses. International Journal of Innovation in Science and Mathematics Education.25, 34-47

3. Develaki, M. (2019): Methodology and Epistemology of Computer Simulations and Implications for Science Education. Journal of Science Education and Technology 28:353-370

4. Ferty, Z. N., Jumadi, W., and Kuswanto, H. (2019):Enhancing Students' Critical Thinking Skills through Physics Education Technology Simulation Assisted of Scaffolding Approach/ IOP Conf. Series: Journal of Physics: Conf. Series 1233 012062, doi:10.1088/1742-6596/1233/1/012062

5. Iancu, C., Chilom,C.G.,(2016). Discovering photosynthesis by experiments. Romanian Reports In Physics, 68(3), 1259-1269

6. Lazăr, E. (2018): The ICT Utility As Means Of Instruction. TeacherAnd Learner-Oriented Perspectives: Annals Of The University Of Craiova, Psychology-Pedagogy,(37), 115-124

7. Mohagheghzadeh, M. S., Mortazavi, S. M. J., Ghasempour, M., Jarideh, S.(2014) The Impact Of Computer And Information Communication Technology Literacy On The Academic Achievement Of Medical And Dental Students At Shiraz University Of Medical Sciences European Scientific Journal, 10(9).

8. Nakakoji, Y., Wilson, R. (2018) First-Year Mathematics and Its Application to Science: Evidence of Transfer of Learning to Physics and Engineering. Education Sciences. 8(1):8.

9. Omeodu, M. D. (2019) . Role of Mathematical Competencies in Enhancing Students' Academic Performance in Physics in Port Harcourt Local Government Area Rivers State. European Scientific Journal, 15(21)

10. Perkins, K., Adams,W., Dubson, M., Finkelstein, N., Reid, S., Wieman, C., LeMaster , R., ( 2006) PhET: Interactive Simulations for Teaching and Learning Physics, The Physics Teacher, 44(1), 18

11. Phet a; available at https://phet.colorado.edu/ro accesed september 2019

12. Phet b; https://phet.colorado.edu/sims/html/waveinterference/latest/wave-interference_en.html accesed september 2019

13. Phet c; available at https://phet.colorado.edu/en/simulation/legacy/davisson-germer

14. Physics -Romanian National Curriculum for XI-XII grades, available at 
https://www.isjcta.ro/wp-content/uploads/2013/06/Fizica_programaF1_F2_clasa-a-XI-a_a-XII-a.pdf

15. Stanescu, M.M., (2017). The advantages of using sensors in ProjectBased Learning of sciences. Proceedings of the 12th International Conference on Virtual learning, 498-503.

16. Ukoh, E. E., (2012) Determining The Effect Of Problem-Based Learning Instructional Strategy On Nce Preservice Teachers' Achievement In Physics And Acquisition Of Science Process Skills European Scientific Journal, 8(17)

17. Wickham, C. M., Girvan, C., \& Tangney, B., Sipitakiat, A., \& Tutiyaphuengprasert, N. (Eds.) (2016): Constructionism and micro worlds as part of a 21st century learning activity to impact student engagement and confidence in physics .Proceedings of Constructionism 2016, Bangkok Thailand (34-41). 